\title{
The Influence of Race and Gender on Family Physicians' Annual Incomes
}

\author{
William B. Weeks, MD, MBA, and Amy Wallace, MD, MPH
}

Purpose: Specialty, work effort, and gender have been shown to be associated with physicians' annual incomes. We hypothesized that provider race might also be associated with differences in family physicians' incomes. Therefore, we conducted a study that used survey data to explore the relationship between provider gender and race and family physicians' annual incomes.

Methods: We used survey responses collected by the American Medical Association (AMA) throughout the 1990s from 786 white male, 20 black male, 159 white female, and 12 black female actively practicing family physicians. We then used linear regression modeling to determine the influence of race and gender on physicians' annual incomes after controlling for work effort, provider characteristics, and practice characteristics.

Results: Female family physicians reported seeing substantially fewer patients and working fewer annual hours than their male counterparts. After adjustment for work effort, provider characteristics, and practice characteristics, black men's mean annual income was $\$ 178,873$, or $\$ 9,309(5.5 \%)$ higher than that for white men (95\% Confidence Interval (CI), $-\mathbf{\$ 1 8 , 4 1 0}$ to $\$ 37,028)$; white women's was $\$ 135,531$, or $\$ 14,579(8.6 \%)$ lower $(95 \% \mathrm{CI},-\$ 25,969$ to $-\$ 3,189)$; and black women's was $\$ 107,733$, or $\$ 36,963(22 \%)$ lower $(95 \%$ CI, $-\$ 71,450$ to $-\$ 2,476)$.

Conclusions: During the 1990s, female gender was associated with lower annual incomes among family physicians, substantially so for black women. These findings warrant further exploration to determine what factors might cause the gender-based income differences that we found. ( $\mathrm{J}$ Am Board Fam Med 2006;19:548-56.)

Female gender has long been associated with lower incomes among US physicians, even after adjusting for work effort. ${ }^{1}$ A 1979 study found that female family physicians had lower incomes but were younger and had different practice arrangements than their male counterparts. ${ }^{2}$ More recent studies that also adjusted for physician age and specialty ${ }^{3-6}$ revealed similar income disparities, although one found that the combination of specialty status, per-

This article was externally peer reviewed.

Submitted 24 February 2006; revised 8 June 2006; accepted 12 June 2006.

From the Veterans Affairs Outcomes Group Research Enhancement Awards Program (REAP), Dartmouth Medical School, White River Junction, VT.

Funding: This work was supported in part by Veterans Affairs Health Services Research and Development Grant REA 03-098. Dr. Wallace was supported by an Advanced Career Development Grant from Veterans Affairs Health Services Research and Development.

Conflict of interest: none declared..

Disclaimer: The views expressed in this article do not necessarily represent the views of the Department of Veterans Affairs or of the US government.

Corresponding author: William B. Weeks, Veterans Affairs Outcomes Group REAP, Dartmouth Medical School, VAMC (11Q), White River Junction, VT 05009 (E-mail: wbw@dartmouth.edu). sonal data, and female internists' less lucrative practice arrangements eliminated income differences. ${ }^{7}$ Less is known about the influence of race on physicians' incomes. In 1972, black physicians were reported to have different practice characteristics than their white counterparts, ${ }^{8}$ and a 1977 article suggested that analyses of the geographic distribution and work characteristics of black physicians should be conducted ${ }^{9}$; however, analyses of differences between black and white physicians' incomes have not been published.

Whether income disparities among physicians is attributable to race or gender is of interest. First, blacks and women represent an increasingly large proportion of medical students, ${ }^{10,11}$ residents, ${ }^{12}$ the overall practicing physician workforce, ${ }^{11,13,14}$ and family physicians. ${ }^{2}$ Second, because black primary care physicians are more likely to care for the underserved $^{15,16}$ as well as the medically indigent and those with greater illness burdens, ${ }^{17}$ their annual incomes might rationally suffer.

The objective of this analysis was to explore the influence of race and gender on the incomes of black and white family physicians, after adjusting 
for work effort, practice characteristics, and provider characteristics that are likely to influence physician incomes.

\section{Methods}

\section{Data Source}

Between 1992 and 2001, the AMA conducted regular telephone surveys of physicians that collected a broad variety of individual physician level data, including weeks and hours of practice, number of patient visits seen, provider characteristics, practice characteristics and physician incomes. ${ }^{18-25} \mathrm{Al}-$ though these references give a summary of statistics for physicians, we obtained the primary data from the surveys conducted between 1992 and 2001 and use those data for our analyses. The survey was designed to provide representative information on the population of all actively practicing, nonfederal physicians who spend the greatest proportion of their time in patient care activities; weights for each respondent were calculated to correct for potential bias created by unit nonresponse, survey eligibility, and to ensure that physician responders reflected the national distribution of physicians. ${ }^{25}$

\section{Survey Methods}

Each year, the telephone-administered survey was conducted on a random sample of physicians from the AMA Physician Masterfile who are eligible for the survey. The AMA Physician Masterfile contains current and historical information on all physicians in the United States, including AMA members and nonmembers, and graduates of foreign medical schools who reside in the United States and who have met the educational and credentialing requirements necessary for recognition as physicians. ${ }^{26}$ The following physicians were excluded from the survey process: doctors of osteopathy, foreign medical graduates with temporary licensure, inactive physicians, physicians who were sampled during the past 5 years, physicians who are on the "do not contact" list, physicians not practicing in the United States, and physicians who have no license to practice medicine. In addition, after initial screening, federally employed physicians and physicians who spent less than 20 hours each week in patient care activities were excluded.

The following field procedures were developed to minimize nonresponse bias: 2 weeks before data collection, advance letters were sent describing the process and the survey; many specialty organizations provided endorsement letters; and summaries of the types of questions to be asked regarding the financial activities of the practice were provided in advance of the survey. In addition, a minimum of four callbacks to respondents were made before abandoning interview efforts, letters encouraging participation were sent to physicians who initially refused participation, and refusal conversion attempts were made by select interviewers. ${ }^{25}$

\section{Survey Weights}

Survey weights were derived by first dividing the AMA Physician Masterfile population and survey respondents into 200 cells defined by specialty, years since the respondent received an MD (doctorate of medicine degree), AMA membership status, and board certification status. Unit response rates were constructed as the ratio of the number of physicians in the population to the number of respondents in each cell. Second, an eligibility correction wasused, as only nonfederal patient care physicians-excluding residents_-are eligible. The eligibility correction divides the subset of the population for which eligibility is known into 40 cells (according to years in practice, AMA membership status, gender, and board certification) and calculates the proportion of physicians in each cell who are eligible. This defines the eligibility weight. The overall weight applied for a given respondent is the product of the unit response weight and the eligibility weight. ${ }^{25}$

\section{Sample}

Although the survey had been conducted for much longer, this analysis was limited to data collected between 1992 and 2001 for two reasons. First, during the study period, physicians were categorized into different specialty groups in a way that allowed for the disaggregation of responses from family physicians and general practitioners. Second, these were the most recent data available for analysis and, therefore, likely to be the most relevant to the currently practicing physician workforce.

A sequential process of eliminating survey respondents was used to ensure that all the physicians included in the analyses were comparable (Figure 1). We were interested in studying actively practicing family physicians, not the minority of physicians who were primarily researchers, medical educators, administrators, or hospitalists. Therefore, 


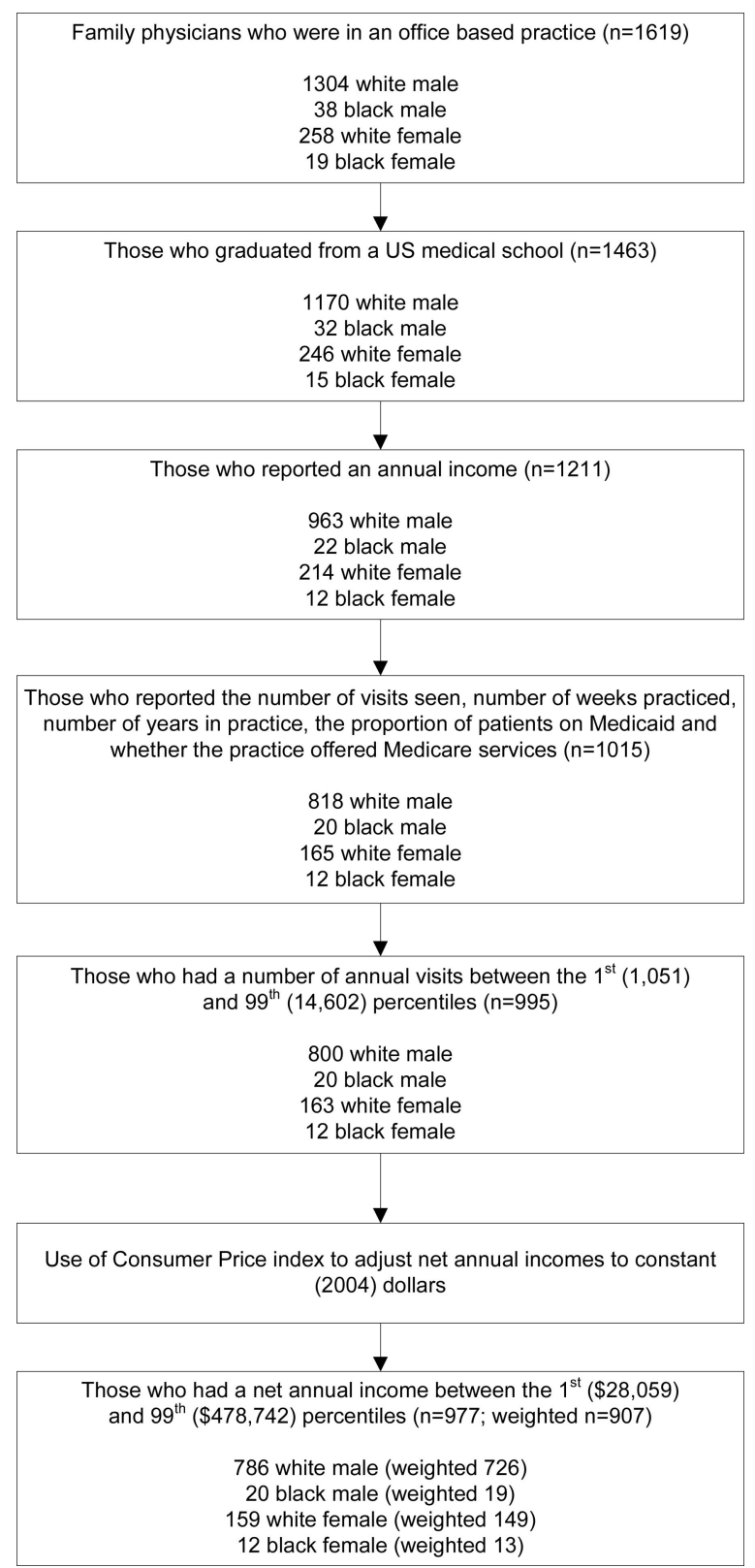

Figure 1. Sequential process of selecting survey respondents to include in the final analysis.

1619 self-identified black or white physicians who were identified as practicing family practice in an "office-based practice" were included as potential subjects in the study, distributed as follows: 1304 white male, 38 back male, 258 white female, and 19 black female family physicians. We initially restricted the sample to those respondents who graduated from a US medical school and provided information on key variables, leaving a total of 1015 family physicians: 818 white males, 20 black males, 165 white females, and 12 black females. Because we were concerned that some of the data reported at the extremes of key variables-namely the number of annual patient visits conducted and the annual reported incomes-were either incorrect or dramatically atypical for practicing family physicians, we excluded respondents who were extreme outliers (less than the 1st percentile and greater than the 99th percentile of the sample) in annual patient visits and net incomes. This process left a total of 977 family physicians available for analysis: 786 white males, 20 black males, 159 white females, and 12 black females. Using survey weights, these respondents represented 906 respondents, or 726 white male, 19 black male, 149 white female, and 13 black female family physicians.

\section{Variables Proposed to Influence Physicians' Incomes}

From the AMA dataset, three types of independent variables that were likely to influence the dependent variable—net annual income-were extracted.

\section{Physician Work Effort}

Although it has been demonstrated that hours worked is an important variable in analysis of physician incomes, ${ }^{3-6,27}$ the number of visits a physician completes each year may also influence annual incomes. Although private practice physicians typically bill based on patient visits, physicians who are employed by health care systems are likely to have either quotas or incentive based production bonuses associated with patient visit volumes such that compensation methods are unlikely to be related to use of health services per person. ${ }^{28}$ Indeed, among the study sample, there was a modest linear relationship between inflation-adjusted annual physician incomes and annual patient visits seen $(r=0.49, P<.001)$ than with annual hours worked $(r=0.28, P<.001)$.

\section{Provider Characteristics}

When making comparisons of physician incomes, age is usually included as a confounding variable. ${ }^{3-6}$ Over the working lifetime, incomes demonstrate an "inverted U" pattern ${ }^{29}$ that typically peaks near age 55 for primary care physicians, ${ }^{30,31}$ or after 20 to 25 years of practicing medicine. To dispel a concern that race or gender might influence the age at which a physician entered medical school, we incorporated the number of years that respondents had been practicing medicine into the analysis instead of physician age. Among the study sample, 
the number of years practicing medicine was highly correlated with age $(r=0.89, P<.001)$. In addition, because practice arrangements, such as having an ownership interest in the practice, has been associated with differences in annual income among physicians, ${ }^{7}$ we included in the analysis whether the physician was an employee of a health care system, as opposed to a full or partial owner of the practice, in the analysis. Finally, because board certification has been associated with higher incomes, ${ }^{32}$ we included board certification status as an independent variable in the analysis.

\section{Practice Characteristics}

Physicians who live in different US Census regions have been shown to have modestly different annual incomes ${ }^{18-25}$; therefore, we collected information on the US Census region in which the practice was located. In addition, because physicians who live in sparsely populated settings may have lower ${ }^{33}$ or higher ${ }^{34}$ incomes, we classified responding physicians' county codes into three categories of metropolitan settings (less than 50,000, between 50,000 and 500,000, or greater than 500,000). Finally, black physicians' annual incomes may reasonably be lower because of their disproportionate service the medically indigent and those who are under- or uninsured. ${ }^{17}$ Therefore, we incorporated into the analysis variables that likely reflect disproportionate service of that population: whether the practice provides Medicare services and the reported proportion of patients in the practice who are on Medicaid.

\section{Calculated and Dummy Variables}

We used the consumer price index ${ }^{35}$ to adjust reported net annual income to constant 2004 dollars-so-called inflation adjusted annual incomes. For instance, to inflate income reported for 1995 to 2004 dollars, we multiplied the reported income in 1995 by the consumer price index in 2004 (188.9) and then divided that figure by the consumer price index in 1995 (152.4). We multiplied the reported number of weeks worked in the last year by the total number of hours worked in the last week and the total number of visits seen in the last week to calculate the annual number of hours worked and the annual number of visits seen, respectively. Because of the "inverted U" relationship between number of years practicing medicine and annual incomes, we constructed dummy variables that re- flected the categorization of years practicing medicine into 5 -year increments, from 0 to 5 years practicing through 40 plus years practicing. Although we used these dummy variables in the regression analysis, we aggregated them into 10 -year increments through 30-plus years practicing for the purposes of demographic comparisons.

\section{Analysis}

We hypothesized that, after adjusting for factors likely to influence physicians' incomes, race and gender would be independently associated with family physicians' incomes. To explore this hypothesis, we used a linear regression model that adjusted for practice and provider characteristics likely to influence physicians' incomes. We used dummy variables for each race-gender combination to calculate regression coefficients and $95 \% \mathrm{CI}$ in a regression model that incorporated the independent variables detailed above and used consumer price index adjusted annual incomes as the dependent variable. We used SPSS statistical software (Version 11.5, Chicago, IL) and survey weights for all analyses. This study was approved by Dartmouth Medical School's Committee for the Protection of Human Subjects, Hanover, NH (CPHS No. 17707).

\section{Results}

After adjusting incomes only for inflation, white male family physicians had mean net annual incomes of $\$ 169,564$ (Table 1). Compared with white men, black men had mean annual inflation adjusted incomes that were $\$ 19,559$ (11.5\%) higher, white women had incomes that were \$34,033 (20\%) lower, and black women had incomes that were $\$ 61,831$ (36\%) lower. Although black male family physicians reported seeing $2 \%$ more visits and working $11 \%$ more hours than their white male counterparts, white and black women reported seeing $25 \%$ and $39 \%$ fewer visits, respectively, and working $12 \%$ and $17 \%$ fewer annual hours, respectively, than white men.

White and black male family physicians had practiced medicine longer than white or black women; no black women who responded to the survey had practiced more than 20 years. Women of either race were more likely to be employees, as opposed to having an ownership interest in the practice. Family physicians' rates of board certifi- 
Table 1. Comparison of inflation adjusted income, work effort, provider and practice characteristics of family physicians, by race and gender (data obtained from the American Medical Association for years 1992-2001).

\begin{tabular}{|c|c|c|c|c|}
\hline & \multicolumn{4}{|c|}{ Family physicians } \\
\hline & \multicolumn{2}{|c|}{ Male } & \multicolumn{2}{|c|}{ Female } \\
\hline & White & Black & White & Black \\
\hline Number of family physicians in the analysis & 786 & 20 & 159 & 12 \\
\hline Inflation adjusted annual income (mean, in 2004 dollars)* & $\$ 169,564$ & $\$ 189,123$ & $\$ 135,531$ & $\$ 107,733$ \\
\hline \multicolumn{5}{|l|}{ Physician work effort } \\
\hline Total annual visits & 6,396 & 6,555 & 4,790 & 3,892 \\
\hline Total annual hours worked & 2,707 & 2,999 & 2,390 & 2,246 \\
\hline \multicolumn{5}{|l|}{ Provider characteristics } \\
\hline Years in medical practice (mean) & 17.8 & 16.9 & 11.9 & 10.9 \\
\hline Less than 10 years $(\%)$ & 14.6 & 15.8 & 31.5 & 23.1 \\
\hline $10-19$ years $(\%)$ & 47.9 & 59.5 & 59.5 & 76.9 \\
\hline 20-29 years $(\%)$ & 23.0 & 10.5 & 7.4 & 0.0 \\
\hline 30 years or longer $(\%)$ & 14.5 & 15.8 & 1.3 & 0.0 \\
\hline \multicolumn{5}{|l|}{ Ownership interest, and board certification } \\
\hline Physician is an employee (\%) & 42.2 & 47.4 & 61.7 & 69.2 \\
\hline Physician is board certified (\%) & 85.7 & 90.0 & 85.8 & 83.3 \\
\hline \multicolumn{5}{|l|}{ Practice characteristics } \\
\hline \multicolumn{5}{|l|}{ Census region of practice } \\
\hline Northeast census region (\%) & 14.3 & 5.3 & 13.5 & 0.0 \\
\hline North Central census region (\%) & 29.5 & 15.8 & 29.1 & 0.0 \\
\hline Southern census region (\%) & 34.7 & 73.6 & 28.9 & 84.6 \\
\hline Western census region (\%) & 21.5 & 5.3 & 28.2 & 15.4 \\
\hline \multicolumn{5}{|l|}{ Practice setting } \\
\hline Less than 50,000 population (\%) & 24.7 & 10.5 & 22.0 & 0.0 \\
\hline Population between 50,000 and 500,000 (\%) & 33.9 & 21.0 & 26.1 & 23.1 \\
\hline Population greater than $500,000(\%)$ & 41.4 & 68.4 & 51.9 & 76.9 \\
\hline \multicolumn{5}{|l|}{ Service population } \\
\hline Proportion of patients on Medicaid (\%) & 12.9 & 14.8 & 15.8 & 26.7 \\
\hline Proportion providing Medicare services (\%) & 99.0 & 100 & 95.3 & 100 \\
\hline
\end{tabular}

${ }^{*}$ We used the consumer price index ${ }^{35}$ to inflation-adjust reported net annual income to constant 2004 dollars. For instance, to inflate income reported for 1995 to 2004 dollars, we multiplied the reported income in 1995 by the consumer price index in 2004 (188.9) and then divided that figure by the consumer price index in 1995 (152.4).

cation were similar for both genders and races. Black family physicians of both genders were more likely to live in the Southern US Census region and less likely to live in the Northeastern or Western regions. Black family physicians were less likely to live in settings with a population less than 50,000 and more likely to live in settings with populations greater than 500,000. Compared with the other groups, a much larger proportion of black female family physicians' service population was enrolled in Medicaid. The vast majority of black and white, male and female physicians provided Medicare services.

The regression model accounted for $28 \%$ of the variance in annual incomes (Table 2). Higher numbers of annual visits were associated with higher incomes, and the anticipated inverted- $U$ lifetime earnings curve was reflected in the model. Althoughboard certification was strongly associated with higher incomes, not having an ownership interest in the practice, living in less populated settings, and serving a higher proportion of Medicaid patients were modestly associated with lower incomes. After adjustment for these variables, black men's mean annual income was \$9,309 (5.5\%) higher than that for white men, although not statistically significantly so $(95 \% \mathrm{CI},-\$ 18,410$ to $\$ 37,028)$. White women's mean annual income was $\$ 14,579$ (8.6\%) lower than that of their white male counterparts (95\% CI, $-\$ 25,969$ to $-\$ 3,189)$; and black women's was $\$ 36,963$ (22\%) lower (95\% CI, 


\begin{tabular}{|c|c|c|}
\hline & Coefficient & $95 \% \mathrm{CI}$ \\
\hline \multicolumn{3}{|l|}{ Physician work effort } \\
\hline Total annual visits & $\$ 12.06$ & $\$ 10.17-\$ 13.96$ \\
\hline Total annual hours worked & $\$ 1.13$ & $(\$ 4.83)-\$ 7.08$ \\
\hline \multicolumn{3}{|l|}{ Provider characteristics } \\
\hline \multicolumn{3}{|l|}{ Years in medical practice (10 to 15 years is referent) } \\
\hline Less than 5 years & $(\$ 38,339)$ & $(\$ 64,237)-(\$ 12,440)$ \\
\hline 5 to 9 years & $(\$ 3,887)$ & $(\$ 16,092)-\$ 8,318$ \\
\hline 10 to 19 years & $\$ 6,672$ & $(\$ 7,103)-\$ 20,446$ \\
\hline 20 to 24 years & $(\$ 520)$ & $(\$ 12,643)-\$ 11,604$ \\
\hline 25 to 29 years & $\$ 1,038$ & $(\$ 18,229)-\$ 20,305$ \\
\hline 30 to 34 years & $(\$ 15,411)$ & $(\$ 31,688)-\$ 865$ \\
\hline 35 to 39 years & $(\$ 34,419)$ & $(\$ 63,795)-(\$ 5,042)$ \\
\hline 40 years or more & $(\$ 19,353)$ & $(\$ 43,563)-\$ 4,858$ \\
\hline \multicolumn{3}{|l|}{ Ownership interest, and board certification } \\
\hline Physician is an employee & $(\$ 5,848)$ & $(\$ 14,491)-\$ 2,795$ \\
\hline Physician is board certified & $\$ 15,980$ & $\$ 4,173-\$ 27,788$ \\
\hline \multicolumn{3}{|l|}{ Practice characteristics } \\
\hline Northeast census region & $(\$ 17,043)$ & $(\$ 30,077)-(\$ 4,009)$ \\
\hline North Central census region & $(\$ 14,576)$ & $(\$ 24,816)-(\$ 4,336)$ \\
\hline Western census region & $(\$ 9,856)$ & $(\$ 20,933)-\$ 1,221$ \\
\hline Less than 50,000 population & $(\$ 5,643)$ & $(\$ 16,638)-\$ 5,352$ \\
\hline Population between 50,000 and 500,000 & $(\$ 13,756)$ & $(\$ 23,086)-(\$ 4,426)$ \\
\hline \multicolumn{3}{|l|}{ Service population } \\
\hline $1 \%$ increase in patient population on Medicaid & $(\$ 187)$ & $(\$ 479)-\$ 105$ \\
\hline Proportion providing Medicare services & $\$ 5,013$ & $(\$ 27,725)-\$ 37,752$ \\
\hline \multicolumn{3}{|l|}{ Race/gendercharacteristics (white male is referent) } \\
\hline Black male & $\$ 9,309$ & $(\$ 18,410)-\$ 37,028$ \\
\hline White female & $(\$ 14,579)$ & $(\$ 25,969)-(\$ 3,189)$ \\
\hline Black female & $(\$ 36,963)$ & $(\$ 71,450)-(\$ 2,476)$ \\
\hline
\end{tabular}

* Our regression model used consumer price index adjusted annual income (2004 dollars) as the dependent variable. Coefficients are denominated in 2004 dollars. Parentheses indicate negative values. Adjusted R square for the model $=0.28$.

$-\$ 71,450$ to $-\$ 2,476)$. Adjusted incomes with 95\% CI for each group are presented as a proportion of white men's adjusted mean annual incomes in Figure 2.

\section{Discussion}

This study examined provider and practice characteristics that were likely to be associated with physicians' annual incomes. Our analysis revealed differences attributable to race and gender in those characteristics. Even after adjusting net annual incomes for observed differences, we found that female gender independently contributed to lower net annual incomes among office based family physicians. Annual incomes for white and black male family physicians were not different; incomes for white and black female family physicians were substantially lower than those for men.

We found a strong association between higher annual incomes and work effort, particularly the number of patient visits. This finding is intuitive: physician reimbursement is commonly based on the volume of patients seen. The finding that female black physicians have a much larger proportion of Medicaid patients in their practices is interesting. Although consistent with previous findings that black physicians are more likely than whites to care for the underserved and medically indigent, ${ }^{15-17}$ in this study, the findings were most pronounced for black women. Our regression analysis confirmed that providing services to a large proportion of patients who are enrolled in Medicaid adversely influence physicians' incomes. Un- 


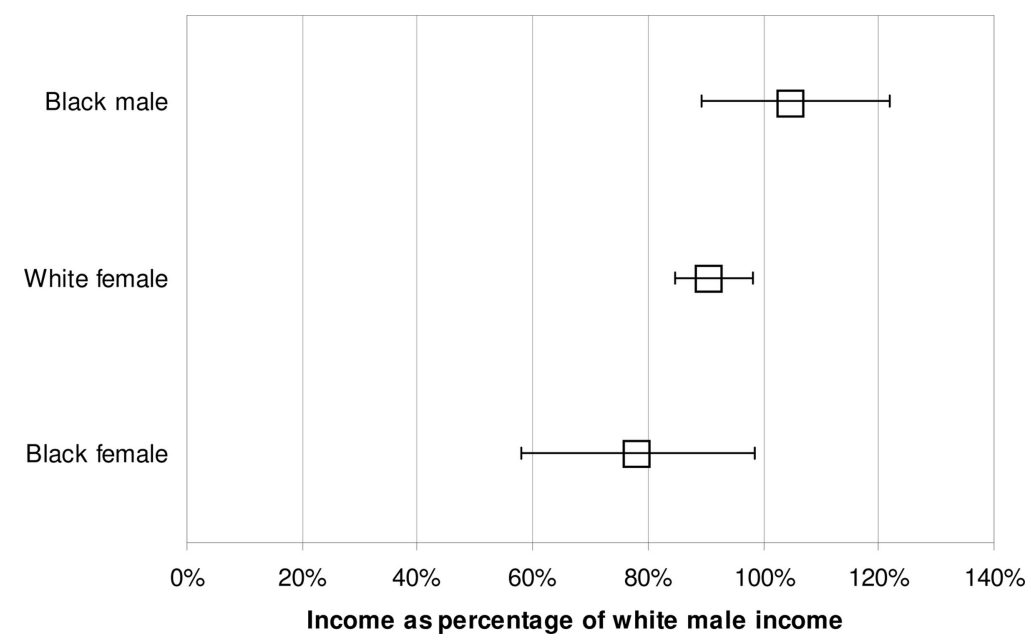

Figure 2. Adjusted annual incomes for black male, white female, and black female family physicians as a proportion of that for white male family physicians, with $95 \% \mathrm{CI}$.

doubtedly, this association reflects the low reimbursement rates provided by Medicaid funded health care services.

The association between higher annual incomes and board certification is consistent with findings from the early 1980s. ${ }^{32}$ This association might be explained in part by a propensity for provider organizations to require board certification for employment, by requirements by third-party payers that providers have board certification, or by market forces that use board certification as a marker for quality that is indirectly reimbursed.

It was disconcerting to find that black and white female family physicians had annual incomes that are discounted compared with that of their male counterparts. Although the anticipated $8.6 \%$ reduction in annual incomes found for white women was similar than that found in other studies that compared work-effort adjusted female to male physicians incomes, ${ }^{3-6}$ those analyses did not take into account the plethora of provider and practice variables that we examined here. Indeed, the only study that incorporated a similar, though not as extensive, complement of variables into the analysis found no difference between male and female physicians' incomes. ${ }^{7}$ Although limited by the small number of respondents, the $22 \%$ anticipated income differential between white male and black female family physicians is daunting, and suggests an additive effect of race and gender on annual incomes for this group.

This analysis has several limitations. First, the number of black respondents to the survey was small; therefore, the ability to generalize findings about the racial differences that we found may be limited. A larger sample of black physicians would improve confidence in these findings. Second, the study was limited by the methods used by the AMA in their conduct of an annual survey of physicians, a survey that demonstrated substantial year-to-year variation in number of respondents and experienced a survey response rate that declined from $71 \%$ to $55 \%$ during the time period examined. However, the ability to combine ten years of data strengthened the study and offered a much more robust dataset than would have been the case had fewer years of data been available. Third, our modeling assumed a linear relationship between hours worked, patient visits and net annual incomes. Our model would not capture nonlinear relationshipsfor instance, should working fewer hours be associated with a disproportionate reduction in practice costs. More sophisticated economic modeling would be required to capture those differences. Fourth, the study was inherently limited by the data available from the survey. Other variables that might influence physicians' incomes, such as the gender- and race-specific differences in charity care provided, and whether the physician practiced obstetrical care (historically a contributor to higher incomes among family physicians ${ }^{36}$ ) were not available in the data source that we used.

Fifth, we were not able to examine differences in the quality of care provided by white and black, male and female family physicians. This is an important limitation-higher incomes might be jus- 
tified for family practitioners who provide higher quality care. However, several studies suggest that female primary care providers provide higher quality of care that their male counterparts: during the period studied, female physicians were more likely to provide preventive care, ${ }^{37-42}$ engage in more positive communication dyads, ${ }^{43,44}$ and provide greater levels of patient satisfaction than their male counterparts. ${ }^{40,45}$ These studies suggest that, to the degree that quality is associated with higher incomes, our findings likely underestimated the income difference associated with gender among family physicians.

Finally, our findings are of an associative, not causative, nature. Additional study is required to determine causal pathways that might be associated with the lower incomes that female family physicians experienced. A variety of potential explanations for our findings may exist-for instance, male family physicians may have more successful negotiation skills, different practice arrangements, different subspecialty practice types, and academic ranks than their female counterparts. However, differences in these factors may themselves be indicators of discrimination; therefore, future efforts will need to discern gender differences not only in outcome measures-adjusted annual incomes-but also in process measures. Further, an understanding of women physicians' perception of any differences-particularly whether they are desired-will be important to delineate in future work.

Despite these limitations, the results of this study suggest that provider gender is independently associated with lower annual incomes among family physicians. These findings should be contextualized, however. Foremost, the anticipation of financial returns should not drive the choice to enter the medical profession; the results presented here are therefore unlikely to dissuade women from entering family practice. In addition, physicians derive many nonfinancial benefits from their roles, including the satisfaction of helping patients, the ability to serve their communities, and the opportunity to model for others of similar backgrounds the advantages of pursuing higher education. These benefits are likely to be highly motivating regardless of physician gender or race.

Although salary differences between men and women may be common and stable among non professionals, ${ }^{46}$ it seems untoward that a profession that embraces equity as a cornerstone of medical practice quality ${ }^{47}$ should tolerate gender-based inequity in pay. Female family physicians have achieved the same level of education, have made the same time commitment to training, and have experienced the same direct and opportunity costs required of such commitment ${ }^{48}$ as their male counterparts. Additional efforts to elucidate the underlying causes of any salary differences and to suggest remedies are warranted.

\section{References}

1. Langwell KM. Differences by sex in economic returns associated with physician specialization. J Health Polit Policy Law 1982;6:752-61.

2. Ogle KS, Henry RC, Durda K, Zivick JD. Genderspecific differences in family practice graduates. J Fam Pract 1986;23:357-60.

3. Ohsfeldt RL, Culler SD. Differences in income between male and female physicians. J Health Econ 1986;5:335-46.

4. Carr P, Friedman R, Moskowitz M, et al. Research, academic rank, and compensation of women and men faculty in academic general internal medicine. J Gen Intern Med 1992;7:418-23.

5. Baker L. Differences in earnings between male and female physicians. N Engl J Med 1996;334:960-4.

6. Wallace AE, Weeks WB. Differences in income between male and female primary care physicians. J Am Med Womens Assoc 2002;57:180-4.

7. Ness R, Ukoli F, Hunt S, et al. Salary equity among male and female internists in Pennsylvania. Ann Intern Med 2000;133:104-10.

8. Thompson T. Selected characteristics of black physicians in the United States, 1972. JAMA 1974;229: $1758-61$.

9. Gray LC. The geographic and functional distribution of black physicians: some research and policy considerations. Am J Public Health 1977;67:519-26.

10. Health, United States. 2004. National Center for Health Statistics: Hyattsville, MD, 2004.

11. AAMC Data Book: Statistical information related to medical schools and teaching hospitals. Washington, DC: The Association of American Medical Colleges, 2000.

12. Brotherton SE, Rockey PH, Etzel SI. US graduate medical education, 2004-2005. JAMA 2005 294:1075-82.

13. Pasko T, Seidman B, Birkhead S. Physician Characteristics and Distribution in the US: 2000-2001 Edition, ed. Division of Survey and Data Resources. Chicago, IL: American Medical Association, 2000.

14. Corbie-Smith G, Frank E, Nickens H. The intersection of race, gender, and primary care: results from the Women Physicians' Health Study. J Natl Med Assoc 2000;92:472-80.

15. Komaromy M, Grumbach K, Drake M, et al. The 
role of black and Hispanic physicians in providing health care for underserved populations. N Engl J Med 1996;334:1305-10.

16. $\mathrm{Xu} \mathrm{G}$, Fields SK, Laine C, et al. The relationship between the race/ethnicity of generalist physicians and their care for underserved populations. Am J Public Health 1997;87:817-22.

17. Moy E, Bartman BA. Physician race and care of minority and medically indigent patients. JAMA 1995;273:1515-20.

18. Gonzalez M, ed. Physician Marketplace Statistics, 1992. Chicago, IL: American Medical Association, Center for Health Policy Research, 1992.

19. Gonzalez M, ed. Physician Marketplace Statistics, 1993. Chicago, IL: American Medical Association, Center for Health Policy Research, 1993.

20. Gonzalez M, ed. Physician Marketplace Statistics, 1994. Chicago, IL: American Medical Association, Center for Health Policy Research, 1994.

21. Gonzalez M, ed. Physician Marketplace Statistics, 1995. Chicago, IL: American Medical Association, Center for Health Policy Research, 1996.

22. Gonzalez M, ed. Physician Marketplace Statistics, 1996. Chicago, IL:American Medical Association, Center for Health Policy Research, 1997.

23. Gonzalez M, ed. Physician Marketplace Statistics, 1997/1998. Chicago, IL: American Medical Association, Center for Health Policy Research, 1998.

24. Zhang P, Thran S. Physician Socioeconomic Statistics, 1999-2000. Chicago, IL: American Medical Association Center for Health Policy Research, 1999.

25. Wassenaar J, Thran S. Physician Socioeconomic Statistics, 2000-2002. Chicago, IL: American Medical Association Center for Health Policy Research, 2001.

26. AMA Physician Masterfile. Available at www.amaassn.org/ama/pub/category/2673.html, American Medical Association: Chicago, IL.

27. Weeks WB, Wallace AE. Time and money: a retrospective evaluation of the inputs, outputs, efficiency, and incomes of physicians. Arch Intern Med 2003; 163:944-8.

28. Conrad DA, Maynard C, Cheadle A, et al. Primary care physician compensation method in medical groups: does it influence the use and cost of health services for enrollees in managed care organizations? JAMA 1998;279:853-8.

29. Polackek SW, Siebert WS, The Economics of Earnings. Cambridge, U.K.: Cambridge University Press, 1993.

30. Weeks WB, Wallace AE, Wallace MM, Welch HG. A comparison of educational costs and incomes of physicians and other professionals. N Engl J Med 1994;330:1280-6.

31. Weeks WB, Wallace AE. The more things change: revisiting a comparison of educational costs and incomes of physicians and other professionals. Acad Med 2002;77:312-9.
32. Becker ER, Culler S, Ohsfeldt R. Impact of board certification on physician practice characteristics. J Med Educ 1985;60:9-15.

33. Weil TP. Attracting qualified physicians to underserved areas. Part 2. Pay physicians more to practice in underserved areas. Physician Exec 1999;25:53-63.

34. Reschovsky JD, Staiti AB. Physician incomes in rural and urban America. Issue Brief/Center for Studying Health System Change 2005;92:1-4.

35. Consumer price index. Available at www.bls.gov/ cpi/. Washington, DC: US Department of Labor, Bureau of Labor Statistics, 2006.

36. Bredfeldt RC, Sutherland JE, Wesley RM. Obstetrics in family medicine: effects on physician work load, income, and age of practice population. Fam Med 1989;21:279-82.

37. Pham HH, Schrag D, Hargraves JL, Bach PB. Delivery of preventive services to older adults by primary care physicians. JAMA 2005;294:473-81.

38. Turner BJ, Amsel Z, Lustbader E, et al. Breast cancer screening: effect of physician specialty, practice setting, year of graduation, and sex. Am J Prev Med 1992;8:78-85.

39. Frank E, Singh SR, Personal and practice-related characteristics of a subsample of US women dermatologists: data from the Women Physicians' Health Study. Int J Dermatol 2001;40:393-400.

40. Bertakis KD, Franks P, and Azari R. Effects of physician gender on patient satisfaction. Jn Am Med Womens Assoc 2003;58:69-75.

41. Kreuter MW, Strecher VJ, Harris R, et al. Are patients of women physicians screened more aggressively? A prospective study of physician gender and screening. J Gen Intern Med 1995;10:119-25.

42. Frank E, Harvey LK. Prevention advice rates of women and men physicians. Arch Fam Med 1996;5: 215-19.

43. Weisman CS. Women and their health care providers: a matter of communication. In: Communication between women and their health care providers: research findings and unanswered questions. Bethesda, MD: National Conference on Women's Health, 1986.

44. Roter DL, M. Korsgaard,. A. Sex differences in patients' and physicians' communication during primary care medical visits. Med Care 1991;29:1083-93.

45. Maheux B, Dufort F, Beland F, et al. Female medical practitioners. More preventive and patient oriented? Med Care 1990;28:87-92.

46. Mishel L, Bernstein J, and Schmitt J. The State of Working America, 2000-2001. An Economic Policy Institute Book. Ithaca, NY: ILR Press, an imprint of Cornell University Press, 2001.

47. Berwick DM. A user's manual for the IOM's Quality Chasm report. Health Aff 2002;21:80-90.

48. Weeks WB and Wallace AE. Long-term financial implications of specialty training for physicians. Am J Med 2002;13:393-9. 